\title{
DETRÁS DEL DEBATE. LA CUESTIÓN COMUNISTA Y LA CRIMINALIZACIÓN EN LA LEY DE REPRESIÓN AL COMUNISMO DE 1936
}

\author{
MERCEDES F. LÓPEZ CANTERA (UBA) \\ Programa de Doctorado en Historia \\ Facultad de Filosofía y Letras - Universidad de Buenos Aires \\ (Puan 430 - CP 1406 - Ciudad de Buenos Aires) \\ mercedes.lopez.cantera@gmail.com
}

\section{Resumen:}

Nuestro propósito es destacar la presencia de la cuestión comunista en el debate por la "Ley de Represión al Comunismo" de 1936 y su vinculación con la cuestión obrera presente en los años treinta. A su vez, nos interesa indicar cómo este proyecto de Ley formó parte de un proceso de criminalización del comunismo que el Estado argentino intentó llevar a cabo durante esa década, por lo que su debate no significó un hecho aislado, constituyéndose como un hito en el desarrollo del anticomunismo de la Argentina de entreguerras.

Palabras clave:

Anticomunismo - Movimiento Obrero - Comunismo - Período de Entreguerras - Historia Argentina

\begin{abstract}
:
Our purpose is to highlight the presence of a communist problem in the debate over the 1936 "Represión al Comunismo" bill and its connection with the labor problem present in the thirties. We want to indicate how this bill was part of a criminalization process of communism that the Argentine government endeavored to advance during that decade, so we shall strive to comprehend this discussion not as an isolated event, becoming a landmark in the development of anticommunism in interwar period in Argentina.
\end{abstract}

\section{Keywords:}

Anticommunism - Labor Movement - Communism - Interwar Period - Argentine History 


\section{DETRÁS DEL DEBATE. LA CUESTIÓN COMUNISTA Y LA CRIMINALIZACIÓN EN LA LEY DE REPRESIÓN AL COMUNISMO DE 1936}

\section{MERCEDES F. LÓPEZ CANTERA (UBA)}

mercedes.lopez.cantera@gmail.com

\section{Introducción}

En noviembre de 1936 se debatió en el Congreso Nacional de la República Argentina un proyecto de ley que penalizaba a quienes empleasen el uso de la violencia o difundiesen propaganda política con el fin de establecer el "régimen de dictadura del proletariado". Se trataba de la Ley de Represión al Comunismo, presentada por el senador del Partido Demócrata Nacional (PDN) por la provincia de Buenos Aires, Matías Sánchez Sorondo. El principal objetivo de este recurso era la proscripción del Partido Comunista argentino (PC), el cual desde el retorno constitucional conservador en 1932 había mantenido una activa posición a pesar de la represión estatal sobre el movimiento obrero. En enero de 1936, el PC había encabezado la gran Huelga de la Construcción, cuyas repercusiones alertaron sobre el nivel de organización adquirido por la clase trabajadora. En consecuencia, la Ley de Represión fue defendida como una herramienta para la defensa del orden político frente a estos conflictos sociales. Sus detractores argumentaron que la misma atentaba contra las garantías constitucionales y ampliaba el control Estatal sobre el sector obrero.

Esta discusión sobre el carácter de la ley se enmarcó en la llamada cuestión obrera, que desde principios de siglo abarcó las problemáticas del mundo del trabajo y en el escenario local de expansión industrial y recuperación económica de los años treinta, volvió a ser parte de la agenda política. Actores como la Iglesia, partidos socialdemócratas y grupos nacionalistas, elaboraron sus propuestas para resolver esas tensiones al tiempo que el activismo de las organizaciones obreras de izquierdas -relacionado a la lucha por el reconocimiento sindical, reclamos sobre las condiciones laborales y la resistencia a la represión- iba en aumento. En este contexto se planteó una segunda cuestión vinculada estrechamente a esta primera: la cuestión comunista. Desde la dictadura de J. F. Uriburu (1930-1932), la estructura represiva del Estado presentó al comunismo como el principal actor a controlar, lo que implicó detenciones a militantes obreros, sean del PCA como de otras izquierdas, sino además la aplicación de censura sobre la prensa obrera, confiscaciones de material literario, de propaganda política, etc. Tras la huelga de la Construcción de 1936 esta problemática adquirió una mayor relevancia.

La relación entre la cuestión obrera de los años treinta y la cuestión comunista ha sido abordada marginalmente por algunos estudios de las últimas décadas. Algunas visiones ya clásicas tendieron a minimizar esa relación. Entre éstas encontramos a Alan Rouquié ${ }^{2}$, donde apareció por primera

\footnotetext{
${ }^{1}$ Sánchez Sorondo, Matías, Represión al Comunismo. Proyecto de Ley, informes y antecedentes, Senado de la Nación Argentina, 1936, p. 1.

2 Rouquié, Alan, Poder militar y sociedad politica en la Argentina, tomo I, Buenos Aires, Emecé, 1981 (primera publicación
} 
vez una afirmación que abonó un sentido común historiográfico: la existencia para la década del treinta de un "anticomunismo sin comunismo", por el que el fenómeno anticomunista resultó un chivo expiatorio de las corrientes reaccionarias. Esta afirmación fue continuada por Loris Zanatta y David Rock ${ }^{4}$, para quienes el "comunismo" fue casi una herramienta retórica en el discurso nacionalista-católico, siendo un enemigo difuso, sin consistencia. Sin embargo otros autores como Sandra McGee Deutsch ${ }^{5}$ mencionaron el predominio del pensamiento anticomunista en el discurso del nacionalismo reaccionario del período, vinculándolo a la presencia de una masa obrera organizada con una fuerte influencia de izquierdas revolucionarias que promovió estrategias políticas, acciones represivas y un discurso anticomunista por parte de los primeros.

Nuestro trabajo parte de la relación entre ambas cuestiones, siendo el debate en el Senado de 1936 una clara ilustración de ello. A su vez creemos que esta discusión parlamentaria se inscribió en un contexto donde la escalada represiva del Estado había ido en ascenso, en particular desde la presidencia de Agustín P. Justo (1932-1938), formando parte de un proceso que encontró un límite en la capacidad de movilización de la clase obrera a partir de 1936. La Ley de Represión al Comunismo constituyó un punto de inflexión en las prácticas de control de Estado y en el discurso anticomunista. Es por ello que nos proponemos analizar los aspectos más relevantes del debate sobre la relación cuestión comunista-cuestión social y cómo en ella se hizo presente uno de los aspectos más notorios del anticomunismo argentino: la criminalización. Para ello tomaremos la presentación y defensa del proyecto por Sánchez Sorondo en las sesiones de noviembre y diciembre de 1936, observando las intervenciones que toman como centro a la cuestión obrera: las de Mario Bravo, Lisandro de la Torre, José Heriberto Martínez y Héctor González Iramain. Los antecedentes al proyecto en materia represiva nos ayudarán a vincular el debate a la criminalización de la que era objeto el comunismo, incluyendo aspectos de la difusión del proyecto y apoyos de sectores clave para enriquecer nuestros dos objetivos.

\section{Prólogo al debate o algunos antecedentes}

Los años treinta constituyeron para la Argentina un escenario complejo. Los cambios institucionales que acarreó la crisis de Wall Street, promovieron una mayor intervención del Estado que implicó el fortalecimiento de la industrialización por sustitución de importaciones y fomentó el crecimiento de una clase obrera industrial ya existente. Con el fin de contener al conflicto social resultante de las transformaciones económicas, el Estado en la primera mitad de esa década buscó la modernización del aparato represivo; esto comprometió a parte del uriburismo pero principalmente al gobierno de Justo, quien invirtió en la Policía de la Capital ${ }^{6}$ y en las FFAA.

La modernización de las fuerzas de seguridad significó para Policía el empleo de distintas herramientas para la represión. Esta institución enfocó ese accionar principalmente en el PC. En 1931 tuvo lugar la creación de la Sección Especial de Represión al Comunismo (SERC), dependencia de la Sección de Orden Político creada en 1910 y encargada del control de acciones políticas que atentaran contra el orden social. Otros recursos fueron el dictado de

en 1978).

3 Zanatta, Loris, Del Estado Liberal a la Nación Católica. Iglesia y Estado en los orígenes del peronismo, 1930- 1943, UnQui Ed., Bernal (Buenos Aires), 1996.

${ }^{4}$ Rock, David, La Argentina Autoritaria, Buenos Aires, Ariel, 1993.

${ }^{5}$ McGee Deutsch, Sandra, Las derechas. La extrema derecha en la Argentina, Brasily Chile 1890-1939, UNQui Ed., Buenos Aires, 2005.

${ }^{6}$ La Policía de la Capital fue el primer órgano de seguridad interna tras la consolidación del Estado Nacional. Si bien su jurisdicción fue la Capital Federal, funcionó como "policía de Estado" hasta ser absorbida por la Policía Federal Argentina (creada en 1943) en enero de 1945. 
contravenciones y la aplicación de la Ley 4144 (de Residencia) ${ }^{7}$. En 1934, un año atravesado por el segundo Estado de Sitio (diciembre de 1933 y julio de 1934), periódicos como Crítica y La Vanguardia -órgano del Partido Socialista (PS) - hicieron públicas denuncias con la SERC por el empleo de tortura entre detenidos obreros. Frente a ello, diputados socialistas interpelaron al Ministro del Interior Leopoldo Melo, quien elevó un informe explicando las razones de la existencia de la SERC y sus actividades desde 1932. El documento analizaba los métodos de protesta de distintos grupos obreros calificados como "delincuentes" o poseedores de una "prédica subversiva", todo ello vinculado a la presencia del comunismo.

Sumado a la negación de la tortura, Melo explicó a la SERC como parte de una "acción preventiva":

"En la República Argentina únicamente existen proyectos y no leyes y esto explica la acción preventiva que en defensa social debe realizar la policía y cuyo frecuente epílogo es la declaración por los jueces de que faltan leyes."

El comunismo era caracterizado por el llamado "Informe Melo" como un nuevo tipo de delito. Esta "nueva forma de delincuencia" no podía ser regulada por el Estado, de ahí la necesidad de la acción preventiva de la Sección. La criminalización no fue el único tema relevante de ese informe. El ministro también diferenció entre esos nuevos delincuentes y aquellos trabajadores con reclamos "legítimos", organizados en gremios de línea sindicalista. Esto implicó separar entre aquellos obreros dispuestos a la negociación con el Estado y patronales - el ministro citaba a la $\mathrm{CGT}^{9}$ - y quienes empleaban la violencia con el único objetivo de instaurar un régimen como el de la Rusia soviética.

En contraposición a lo expuesto por el Ministro, el Socorro Rojo Internacional (SRI) publicó un informe en el que se detallaba la actuación de la SERC en los primeros años de la presidencia de Justo. El SRI fue una organización creada en 1922 con el fin de asesorar legalmente o defender a presos políticos a nivel internacional. Por estas acciones y por su vinculación con la URSS, el Socorro fue acusado por el propio Melo y por grupos nacionalistas de brindar a los "agentes del desorden social" una nueva estrategia de defensa: la ayuda jurídica. A pesar de esa acusación y de la persecución que los abogados de esa institución sufrieron, el SRI publicó su informe "Bajo el Terror de Justo" ${ }^{\prime 10}$. Este documento señalaba que las detenciones a militantes obreros se realizaban bajo figuras contravencionales como el caso de "portación de armas" o por "instigación a cometer delitos"; casi todos los detenidos se encontraban en plena actividad huelguística o reunidos en sus agrupaciones o partidos como en celebraciones públicas vinculadas por lo general a actos antifascistas. También se detenía a militantes que estaban difundiendo material de propaganda o realizando pintadas en referencia al "comunismo" o a la "revolución".

Todos éstos eran acusados de realizar "actividades comunistas". De acuerdo al SRI y al "informe Melo", éstas consistían en incitación al delito, atentado armado contra la autoridad, portación de armas, atentado contra la libertad del trabajo y daños causados por inscripciones o pintadas

\footnotetext{
${ }^{7}$ En 1902 fue aprobada la Ley 4144 que establecía la deportación sin juicio previo a todo aquél residente extranjero que perturbara el orden público. La misma fue ideada para ser aplicada particularmente contra militantes obreros extranjeros.

8 Melo, Leopoldo, Mensaje contestando el pedido de informes acerca de las razones que determinaron la creación en la Policía de la "Sección especial de represión contra el comunismo", Archivo de la Honorable Cámara de Diputados, legajo nro. 115, 8 de agosto de 1934.

9 En noviembre de 1933 la central, en cuya dirección predominaba la línea sindicalista, elevó un comunicado de prensa en el que la misma desvinculaba a los obreros de sus organizaciones de los actos violentos objeto de represión policial. Confederación General del Trabajo, Comunicado de Prensa, 8 de noviembre de 1933.

10 Bajo el terror de Justo, ediciones del SRI, septiembre-octubre, 1934.
} 
comunistas. Las torturas fueron detalladas y clasificadas en el informe del Socorro, indicando que su aplicación formaba parte de la cotidianeidad del detenido. Por su parte el diario Crítica reflejó no sólo este tipo de prácticas contra detenidos políticos obreros sino también hostigamientos contra los abogados defensores de estos presos.

Como observamos, el debate en la Cámara de Senadores de 1936 no fue un hecho aislado en relación a la represión anticomunista y la cuestión obrera. Por otra parte, la presentación de ese proyecto ya había tenido lugar por primera vez en 1932, también con el aval de la Comisión Popular Argentina contra el Comunismo (CPACC), organización nacionalista fundada ese mismo año por Carlos Silveyra ${ }^{11}$. En esa oportunidad, Sánchez Sorondo y la CPACC dieron inicio al debate sobre la necesidad de controlar las "acciones comunistas", presentando un informe que enumeraba los actos violentos y se explicaba la "penetración roja" en el sector obrero desde la primera posguerra. Ello fue acompañado por una importante movilización de la propia CPACC el 20 de Agosto de 1932, difundida por militantes y medios nacionalistas, y algunas emisoras radiales ${ }^{12}$. Ambos proyectos, el del '32 y el del '36, hicieron hincapié tanto en la violencia política como en la difusión de propaganda, que consideraban en ascenso tras la "apertura democrática" realizada por Justo.

El Estado argentino volvía a plantear la cuestión social ${ }^{13}$ de principios de siglo ahora en conexión directa con la cuestión comunista. Para 1936, el comunismo era caracterizado como un crimen por la policía, el Estado diferenciaba entre reclamos legítimos y reclamos no legítimos y los trabajadores incluidos en esa segunda categoría eran acusados de querer destruir el régimen político constitucional. Estos elementos tomaron otro cariz al estallar en enero de 1936 la Gran Huelga de la Construcción.

Desde octubre de 1935 los sindicatos de la rama de la construcción habían decretado paro de actividades con el fin de reclamar mejoras salariales y el reconocimiento de sus organizaciones ${ }^{14}$. Esta protesta fue dirigida por la Federación Obrera de los Sindicatos de la Construcción (FOSC), cuya mayoría estaba representada por el Sindicato de Obreros Albañiles, Cemento Armado y Anexos, dirigido por comunistas. A partir de diciembre algunas organizaciones anarquistas decidieron solidarizarse; para enero de 1936 se declaró la huelga general, logrando el apoyo de sesenta y ocho entidades obreras. La huelga comprometió a toda la ciudad de Buenos Aires, al Conurbano y a la ciudad de La Plata. Organismos de prensa como La Nación resaltaron la

\footnotetext{
11 Carlos Silveyra, militante nacionalista, investigó sobre el accionar del PCA elaborando la hipótesis de una penetración del comunismo en el Estado y sociedad argentinos. El Comunismo en la Argentina fue el nombre de esa investigación que, si bien varios capítulos del texto caen en una visión paranoica del avance del "terror rojo", lo cierto es que realiza una minuciosa reconstrucción de la estructura del PCA, sus actividades y sus miembros, basándose en la información que Silveyra fue obteniendo a través de infiltrados en el movimiento obrero y en el PCA entre los años 1931 a 1936 con ayuda de la policía.

12 Rubinzal, Mariela, El Nacionalismo frente a la cuestión social en la Argentina. Discursos, representaciones y prácticas de las derechas sobre el mundo del trabajo, Tesis Doctoral, La Plata, Universidad Nacional de La Plata - Facultad de Humanidades y Ciencias de la Educación, 2012, pp. 183-186.

${ }^{13}$ En la primera década del siglo XX, el aumento de la conflictividad obrera inauguró la llamada cuestión social por la que intelectuales y políticos se preguntaron sobre las raíces de esos problemas y buscaron soluciones que abarcaron desde unas pocas medidas de regulación laboral hasta la represión.

14 Para una mayor comprensión de estos hechos se recomienda el trabajo puntual de Nicolás Iñigo Carrera, $L a$ estrategia de la clase obrera. 1936, Buenos Aires, Ed. PIMSA, 2000; para otros más generales sobre la situación del movimiento obrero de esos años: Matshushita, Hiroshi, Movimiento obrero argentino, 1930-1945. Sus proyecciones en los orígenes del peronismo, Buenos Aires, Ed. Siglo Veinte, 1983; Korzeniewicz, Roberto, "Los conflictos laborales entre 1930 y 1943”, en Desarrollo Económico, vol, 33 nro 131, Buenos Aires, 1993; Del Campo, Hugo, Sindicalismo y peronismo. Los comienzos de un vinculo perdurable, Buenos Aires, Siglo XXI, 1983, entre otros.
} 
violencia de los manifestantes por sobre las raíces del conflicto ${ }^{15}$.

Las consecuencias fueron diversas. En primer lugar, el Estado Nacional debió reconocer a los organismos sindicales involucrados en el conflicto. En paralelo a ello, tanto el Departamento Nacional de Trabajo (DNT) como otros Departamentos provinciales de esa índole, profundizaron sus actividades de mediación en distintos conflictos laborales ${ }^{16}$. Algunas provincias desarrollaron estrategias represivas como el caso paradigmático del gobierno de Manuel Fresco en la provincia de Buenos Aires (1936-1940) y su decreto de "Prohibición de propaganda comunista" en mayo de ese año. Por otra parte, pero no menos importante, el PCA logró consolidarse como fuerza política dentro del movimiento obrero. Esto se combinó con la llamada estrategia de Frente Popular (FP); en 1935 la III ${ }^{\circ}$ Internacional (o Internacional Comunista, IC) planteó el enfrentamiento contra el autoritarismo del fascismo y de las democracias afines al mismo, lo que significó la alianza del comunismo con otras corrientes de izquierda y la socialdemocracia. Los FP involucraron al PCA y al PS, que a su vez participaban de la CGT Independencia, una fracción de la central que se separó en 1935 de otra dirigida por sindicalistas.

El prólogo al debate por la Ley de Represión presentaba un entramado de diversos actores y situaciones. En primer lugar, una política represiva del Estado en transformación, más específica, dirigida a un tipo particular de trabajador. Por su parte el movimiento obrero se encontraba reactivando su lucha; la huelga general de principios de ese año demostró la capacidad de movilización que la clase trabajadora urbana estaba adquiriendo. Finalmente, el PC se constituía como un partido que establecía alianzas políticas para constituir un frente democrático, interesado en participar en elecciones, quizás algo alejado de sus objetivos originales revolucionarios pero consolidando una nueva herramienta para participación en la política estatal.

\section{E1 “delito comunista” y la cuestión obrera en el debate}

El 2 de junio de 1936 la CPACC realizó por segunda vez el pedido de consideración del proyecto de Ley de Represión al Comunismo ante el Senado de la Nación. En su presentación escrita argumentaban que el comunismo era "un sistema de delincuencia social" y aclaraban que la ley buscaba controlar los mecanismos legales de acción comunista -el PC para el caso- y los ilegales, a saber: infiltración en sindicatos, participación en otros organismos y asociaciones estudiantiles, culturales, etc. Finalmente, ese texto enfatizaba que el punto máximo de ese avance comunista había sido la Huelga de la Construcción de ese año ${ }^{17}$.

En octubre, el diario La Nación señaló la necesidad de dictar una ley nacional contra el comunismo, nuevamente caracterizado como una acción delictiva de dimensiones mundiales ${ }^{18}$. La falta de recursos legales para llevar a cabo una "acción defensiva" era uno de los principales argumentos junto a la criminalización. Esta "necesidad de la ley" fue expresada también por los gobiernos provinciales de Salta y Mendoza para amparar sus decretos de represión al comunismo $^{19}$. No es menor señalar que desde el anunciado retorno a la "normalidad constitucional" por Justo en 1932, el Estado buscó la criminalización de actividades políticas con

\footnotetext{
15 "Dio margen a numerosos actor de violencia la huelga general de ayer" y "Hubo diversos tropiezos en los servicios ferroviarios y tranviarios”, en La Nación, 08/01/1936, nro. 23143, año LXVII, p. 8; El Segundo dia de huelga. Hubo escenas de violencia aunque menos importantes, 09/01/1936, en La Nación, nro. 23144, p. 9.

${ }^{16}$ Korzeniewicz, Roberto, op. cit.

${ }^{17}$ CPACC, "Al Sr. Presidente del H. Senado de la Nación”, folios 3 y 4, 2 de junio de 1936.

18 "Represión al comunismo" (editorial), La Nación, 16/10/1936, nro. 23424, año LXVII, p. 6

19 Por un lado en clara referencia al caso de la gobernación de Fresco en Provincia de Buenos Aires y por otro, ejemplos como el caso salteño: "Salta. Dio un decreto sobre represión al comunismo el Ejecutivo provincial", en $L N, 4 / 11 / 1936$, nro. 23443, año LXVII, p. 7. "Límites de acción contra el comunismo", en $L N, 2 / 11 / 1936$, nro. 23441, año LXVII, p. 6.
} 
el fin de avalar su represión en un marco de legalidad, siendo el "Informe Melo" el ejemplo paradigmático ya mencionado. Por el contrario, el diario La Prensa expresó su disconformidad con el proyecto ya que según su apreciación era deber de la Constitución sancionar a toda propaganda que promoviera el atentado contra el sistema democrático y no a un partido político en particular, ya que eso podría llevar a violar las garantías individuales. La propuesta de este órgano de prensa era que el propio gobierno regulara y controlara a todo el sistema de partidos políticos y no tomara medidas en relación a uno ${ }^{20}$.

Ambos justificativos, la criminalización y la "necesidad de la ley", fueron desarrollados en la defensa que encaró el senador Matías Sánchez Sorondo el 24 de noviembre de ese año en el Senado de la Nación. Al respecto, comenzaremos observando la caracterización del comunismo como un delito. De acuerdo al razonamiento del senador Sorondo, las acciones criminales resultaban la vía natural por la que el comunismo podría llevar a cabo sus objetivos revolucionarios:

"Y no se me diga que toda revolución ocasiona muertes que no se califican de asesinato pérdidas de propiedad- que no se califican de robo; -estragos - que no se califican de devastación; -clima conmovido- que no se califique de terror. No. En las revoluciones meramente políticas la muerte y los estragos son consecuencias de la acción. (...) como no quiere propiedad privada, tomará toda la propiedad para dársela al Estado: el robo ya no se llamará robo, se llamará propiedad colectiva".

El comunismo era una ideología destructiva cuyo verdadero objetivo era el de "Matar a las patrias" $^{\prime 22}$ : desarticular todas las bases de las instituciones y todos aquellos principios sociales del Estado y la sociedad argentinos. Entre aquellos "principios sociales de la Nación" se hallaba el derecho a la libertad del trabajo, una acusación presente desde los años veinte entre los nacionalistas y en entidades patronales de tendencia conservadora como la Asociación del Trabajo $^{23}$. Desde este punto de vista las acciones de huelgas o boicot impulsadas por organizaciones de izquierda revolucionaria atentaban contra los derechos de los mismos trabajadores. En su argumentación, S. Sorondo vinculó a diversos casos de protestas obreras con el PC; la huelga de la Construcción volvió a ser mencionada a través de citas referidas a sus preparativos en órganos de prensa del PC (no especifica cuáles) de los meses de agosto, septiembre y noviembre, donde se promovía la unión obrera, se celebraba la huelga y se enunciaban los enemigos de la clase trabajadora: el latifundio, la reacción y el imperialismo. Sorondo, buscando probar la dependencia externa del PC, indicaba que esas declaraciones se conectaban directamente con las realizadas por la Internacional Comunista (IC). El comunismo argentino significaba para los adherentes a ley el promotor de los conflictos obreros existentes en el período y un agente de intereses externos.

Reforzando la idea de la "necesidad de la ley", el senador indicó la existencia de un "vacío" en el sistema penal para enfrentar a los delitos comunistas. Según su postura, leyes como la de Residencia o la Ley de Defensa Social ${ }^{24}$ contemplaban sólo la acción política del militante/delincuente y no la difusión de propaganda, resultando finalmente insuficientes ante ese

\footnotetext{
20 "Límites a la propaganda política", en La Prensa, año LXVIII, nro. 24358, 12/11/36, p. 6.

${ }^{21}$ El subrayado es del original. Cámara de Senadores de la Nación, Diario de Sesiones, Sesión 10 de diciembre de 1936, p 1699.

${ }^{22}$ Cámara de Senadores..., Sesión 10 de diciembre de 1936, p. 1699.

23 Para un análisis del desarrollo de esa organización ver: Rapalo, María Ester, Patrones y obreros. La ofensiva de la clase propietaria, 1918-1930, Buenos Aires, Siglo XXI, 2012.

${ }^{24}$ Dictada en 1910, la Ley de Defensa Social habilitaba al Poder Ejecutivo a arrestar a todo sospecho de adhesión al anarquismo.
} 
nuevo enemigo complejo e inexistente para cuando fueron elaboradas. El nuevo proyecto, por el contrario, apuntaba a controlar o eliminar a "cualquier teoría destructora del orden social", lo que significaba atacar tanto a las "actividades comunistas" como a las tareas de propaganda. Estas últimas eran centrales para la organización del PC y constituían un elemento nuevo; hasta ese momento no se habían registrado tareas de difusión como las realizadas por los diversos organismos de ese partido. Si bien ese objeto de control apareció como un nuevo eje dentro de las propuestas represivas de los años treinta, resultó uno de los puntos de mayor rechazo de la ley. Ante las acusaciones contra el proyecto por violación de las libertades individuales, Sánchez Sorondo subrayaba que el problema no era enseñar sobre el marxismo con fines "científicos" o "académicos", sino enseñar:

“... con fines de proselitismo comunista, para ganar adherentes al partido, haciendo conocer sus teorías, su propaganda y práctica.(...) Así enseñar desde la cátedra el sistema económico comunista con fines científicos, no es considerado delito por el proyecto, pero lo es, utilizar esa enseñanza para inducir a sus oyentes a que se afilien al comunismo con el fin de subvertir el orden social existente..."25

De acuerdo a sus argumentos, su proyecto no apuntaba a reprimir ejemplos del primer caso, lo que sí equivaldría a una violación de derechos, sino los del segundo; diferenciar entre uno y otro sería competencia del Poder Judicial.

Lo cierto es que el control de la propaganda comunista resultó una de las principales razones de apoyo de distintos organismos al proyecto, en particular aquellas instituciones de identidad católica. Por ejemplo, la Acción Católica Argentina (ACA) señalaba que la difusión de propaganda comunista del PC incitaba a actividades fuera de la ley con fines precisos ${ }^{26}$. Esta organización recurría a la caracterización del PCA como ajeno al bienestar de la Nación y exigía el fomento de leyes sociales que protegieran a los trabajadores y asistieran sus necesidades. Los Centro de Estudiantes Universitarios y Secundarios y Centro de Estudios Sociales de la Obra Don Bosco de San Isidro, repetían este último argumento insistiendo en el empleo de leyes económicas y sociales por el Estado para evitar el avance de las izquierdas revolucionarias ${ }^{27}$.

No es extraño encontrar argumentos dentro del catolicismo vinculados a la legislación laboral. Desde varias décadas atrás, la Iglesia católica había buscado en el marco de la doctrina social ${ }^{8}$ ganar terreno en el ambiente obrero; en los años treinta, el desarrollo de estrategias frente a la cuestión obrera se tornó central para esa institución. Un ejemplo de esta política fue la obra de Monseñor Miguel de Andrea a través de la Federación de Asociaciones Católicas de Empleadas como así la continua actividad de los Círculos de Obreros Católicos, creados a fines del siglo XIX. Los Círculos expresaron su total apoyo al proyecto en debate dado que éste pondría fin a la propaganda comunista, a la que caracterizaban como anticristiana, antipatriótica y antisocial ${ }^{29}$. Por otra parte, otra de las cuestiones señaladas por estos grupos católicos fue la violencia política ejercida por el comunismo. En este caso, por la Asociación de Hombres Católicos y el Círculo de Obreros de Rosario, que denunciaron en sus cartas de apoyo al proyecto el atentado contra las instituciones políticas y religiosas por parte de las acciones comunistas. Esa violencia ejercida era atribuida por estas agrupaciones al autoritarismo del régimen ruso, nuevamente remarcado como

\footnotetext{
25 Cámara de Senadores..., Sesión 10 de diciembre p. 1696.

26 ACA, Al Señor Presidente del Honorable Senado de la Nación, 9 de diciembre de 1936, Buenos Aires, Argentina.

${ }^{27}$ Centro de Estudiantes Universitarios y Secundarios y el Centro de Estudios Sociales de la Obra Don Bosco de San Isidro, Al Señor Presidente del Honorable Senado de la Nación, 10 de diciembre de 1936, Buenos Aires, Argentina.

${ }^{28}$ Nos referimos a la influencia de la encíclica Rerum Novarum (RN) y la obra de León XIII.

29 "Represión del comunismo", en Lábaro, octubre de 1936, nro. 14, año II, p. 2; "La Propaganda comunista", en Lábaro, diciembre de 1936, nro. 16, año II, p. 3.
} 
el resultado final de esas acciones ${ }^{30}$.

Un segundo punto nos remite a las estrategias del comunismo y del PC durante los años en cuestión, dentro de las cuales el FP resultó la mayor preocupación entre el anticomunismo. De acuerdo a los argumentos de Sánchez Sorondo, el FP era una medida que "disfrazaba" al PC como un partido democrático, ya que empleaba estrategias electorales y apuntaba a competir contra otras fuerzas políticas ${ }^{31}$. Y era una estrategia política que obedecía a la IC, lo que significaba para éste senador simplemente una medida política rusa, externa, que recurría a acuerdos con otros partidos democráticos como también hacía uso de los llamados "Frentes antifascistas":

"Y es curioso, señores senadores, lo oirán con cierto recelo y sorpresa, ver que el elenco de casi todos estos frentes es el mismo; son, mutatis mutandi, de acuerdo con su clase, edad, cultura y sexo, los que intervienen en el frente antiguerrero, en el frente antiimperialista, en las agrupaciones pro paz, en la agrupación para la defensa de los presos y de sus familias...”

El comunismo argentino era un temor real: apuntaba a tener representación en el Estado y además estaba organizado. Sorondo señalaba que a diferencia del sindicalismo y el anarquismo, el comunismo logró desarrollar una importante estructura política tanto por el mismo partido como por otras entidades con las que mantenía vínculo o directamente le pertenecían. Sobre este punto es interesante mencionar el trabajo de César Seveso ${ }^{32}$ sobre los debates por este proyecto, tanto de 1932 como de 1936. Seveso presenta las pruebas emitidas por S. Sorondo y Silveyra acerca del ascenso del PCA en materia de estructura (publicaciones, propaganda), elementos que le sirven al autor para darle un sustento real al "miedo anticomunista"33.

El senador señaló tres organizaciones que consideraba claves en el avance comunista. A saber: Federación Juvenil Comunista, la Federación de Estudiantes Secundarios y Especiales (FAESE) y el SRI. En relación a las dos organizaciones estudiantiles, el material con el que el senador documentaba sus relaciones con el PC trataba de informes policiales sobre distintos encuentros en el marco de la Segunda Convención de Estudiantes Secundarios de julio de $1936^{34}$. También incluyó a la Federación Universitaria Argentina, la cual respondió al senador aclarando su no pertenencia al PC durante el debate. Mención aparte merecen las apreciaciones de S. Sorondo sobre el SRI, blanco predilecto de las críticas de quienes se identificaban con la lucha anticomunista. En este caso, el senador retomó esas denuncias de la SERC señalando su complicidad a la hora de ayudar a la liberación de detenidos políticos, argumento ya empleado por el Estado en su momento. A ello agregó los vínculos del SRI con la Agrupación de Intelectuales Artistas Periodistas y Escritores (AIAPE) y otras organizaciones de ayuda legal como la Asociación Jurídica Argentina ${ }^{35}$. Debemos remarcar en este punto que las acusaciones del senador apuntaban directamente a aquellas organizaciones relacionadas a la lucha antifascista,

\footnotetext{
30 Asociación Nacional de Hombres Católicos, Al Señor Presidente..., 4 de septiembre de 1936, Vera, Santa Fe, Argentina; Círculo de Obreros Católicos de Rosario, Al Señor Presidente...(telegrama), 28 de noviembre de 1936, Rosario, Sante Fe, Argentina.

${ }^{31}$ Cámara de Senadores..., Sesión 26 de noviembre, pp. 1591- 1592

32 Seveso, César, "A new Law for a new crime: Anticommunism in Argentina 1930-1940", en Journal of Iberian and Latinoamerican Studies, 13:1, July, 2007.

33 También José Luis Ubertalli menciona la importancia dada a las organizaciones del PC en la investigación de Sánchez Sorondo. Ubertalli, José Luis, El enemigo rojo. La represión al Comunismo en la Argentina, Buenos Aires, Acercándonos ediciones, 2010.

${ }^{34}$ Cámara de Senadores..., sesión del 3 de diciembre, pp. 1636-1640.

35 Esta entidad envió documentación en el que aclaraba la falta de vínculos con el Socorro, remarcando su carácter "por encima de las ideologías". Asociación Jurídica Argentina, Carta al Honorable Senado de la Nación, 30 de noviembre de 1936.
} 
tal es el caso de las citadas. Estos argumentos sugerían la complicidad entre el "comunismo criminal" y el antifascismo, buscando descalificar a este último.

La estructura descripta era para S. Sorondo una clara evidencia de la existencia del comunismo en Argentina y su tono crítico volvía en este punto para denunciar la complicidad de quienes negaban a ese actor. Por un lado, el senador cuestionó a aquellos representantes que alegaban la no necesidad de esta ley por no existir un peligro comunista real en el país. De esa manera citaba diversos ejemplos de negación del comunismo: por ignorancia, en defensa de las libertades individuales, por oposición al comunismo o por comunistas. Sea una razón u otra, S. Sorondo los calificaba o de irresponsables o de cómplices.

Esta negación del comunismo era para el senador otra estrategia del propio PC para encubrir su verdadera naturaleza: el internacionalismo. Según Sánchez Sorondo el PC se presentaba como un partido nacional cuando no lo era, haciendo gala de su "defensa de la soberanía" cuando él mismo la estaba violando. De hecho, durante toda su exposición, el senador se refirió al PCA como "Sección Argentina de la Internacional Comunista", ya que obedecía a otro Estado, que es la "Dictadura de los dictadores (sic) de Moscú". De esta afirmación se desprendió una serie de explicaciones sobre los vínculos $\mathrm{PC}^{-\mathrm{III}^{\circ}}$ Internacional, que incluyó los nombres de los dirigentes locales, menciones a los periódicos del partido (Hoy, Orientación, La Internacional) y citas completas de informes del partido local a la $\mathrm{IC}^{36}$ donde se analizaba la situación económica y política argentina. En este marco, podemos incluir la alerta que la CPACC citaba en relación a otros organismos impulsados por el PC, como Unidad Latinoamericana y el Comité de Unidad Sindical Clasista (CUSC) ${ }^{37}$, a los que señala en tanto otras pruebas de la infiltración. Por otra parte, la mención al militarismo ruso agudizaba el peligro que S. Sorondo describía; en este caso, su argumento apuntaba a que la dependencia de ese partido era en relación a un país cuya capacidad militar había ido in crescendo en menos de una década ${ }^{38}$.

La exposición-defensa de Sánchez Sorondo encontró posiciones de apoyo y de rechazo que retomaron las dos cuestiones presentes en su desarrollo. Por un lado, la criminalización del PC o de la ideología comunista pasó a ser ratificada por quienes validaron el proyecto. En general, quienes rechazaron la imagen de un peligro comunista lo hicieron relativizando o minimizando la caracterización de la estructura del PC, aludiendo en su mayoría que ese partido no era la amenaza mencionada. La cuestión obrera, por el contrario, encontró en todas las posiciones una centralidad notoria. Para los detractores de la ley, la misma aparecía como el resultado de la inoperancia estatal en materia de conflictos sociales; para los promotores, la conflictividad existente era motivo de la expansión de las izquierdas y coincidían con los primeros en que era el Estado el responsable de resolverlo. Para analizar estas posiciones tomaremos las presentaciones de los senadores del PS por la Capital Federal, Mario Bravo y del Partido Demócrata Progresista por Santa Fe, Lisandro de la Torre, opositores al proyecto, y los casos de José Heriberto Martínez del PDN, y Héctor González Iramain del Partido Socialista Independiente, ambos a favor de la ley y pertenecientes a fuerzas políticas de la Concordancia, la alianza política que había llevado a la presidencia a Justo.

\footnotetext{
${ }^{36}$ Por ejemplo, párrafos del documento enviado por la III Internacional en julio de 1936 para la celebración del IX Congreso del PCA.

${ }^{37}$ Con Unidad Latinoamericana el senador hacía referencia a la Confederación Sindical Latinoamericana creada en 1929, entidad que nucleó regionalmente a aquellas organizaciones sindicales comunistas. El CUSC fue creado en ese mismo año y su objetivo fue organizar una central sindical liderada por los comunistas como una alternativa a las centrales de tendencia sindicalista o reformista.

38 Aquí S. Sorondo describe con detenimiento el alcance del poder armamentista de la URSS como así menciona con ironía cuál es la paz que la ideología comunista pretende lograr con un país tan militarizado. Cámara de Senadores..., Sesión 3 de diciembre, pp. 1649-1650.
} 
La primera palabra crítica al proyecto de ley fue la de Mario Bravo, quien centró su argumentación en demostrar la ausencia o limitaciones del accionar del Estado en materia de conflictos sociales-obreros, siendo la represión la herramienta usualmente empleada ${ }^{39}$. De acuerdo a este razonamiento, el Estado argentino y su clase dirigente nunca se responsabilizaron de las condiciones de la clase trabajadora. Por el contrario, ante la conflictividad emergente recurrió a "chivos expiatorios", para lo cual cita el caso de la inmigración y la Ley de Residencia. La ley de Represión al Comunismo resultaba para Bravo otro ejemplo de "solución fácil", presentada como un medio para "moralizar" al trabajador, para alejarlo de las malas influencias o eliminar aquellos actores corruptores del trabajo. De acuerdo al senador, detrás de ese justificativo se encerraba el verdadero objetivo, la represión, dirigida contra la clase obrera en particular, no contra todo el cuerpo social como abogaban sus defensores.

El interés del senador socialista se concentró en demostrar el abandono del Estado en relación a las demandas obreras. Para ilustrar ello, describió las huelgas y protestas existentes entre fines de la década de 1920 y las ocurridas durante el gobierno de Justo. Además de ello, Bravo acompañó su intervención con distintos anexos vinculados a este tema. Uno primero presentaba datos referidos a organizaciones o asociaciones obreras existentes en Argentina, junto a las fluctuaciones del costo de vida entre enero de 1933 a 1936 y las variaciones de precios de alimentos básicos de 1935 a $1936^{40}$. El segundo anexo constaba de información vinculada al conflicto obrero: pliegos de condiciones presentadas por distintos sindicatos, número de huelgas entre 1927 a 1936, y un documento acerca del conflicto algodonero de esos años vinculado al reconocimiento sindical ${ }^{41}$.

La represión del Estado materializada en las leyes citadas como en el proyecto era para Bravo la respuesta a la situación existente en el país. Sin embargo, indicaba al mismo tiempo que en esta oportunidad la herramienta de control se había tornado más específica que otras legislaciones conocidas. Este proyecto buscaba no dejar lugar a interpretaciones sobre quién debía ser aplicada, apuntando a destruir a la acción sindical, como parte de un proceso de control estatal, que de acuerdo al senador podía verse ejemplificado en la legislación de Manuel Fresco en la provincia de Buenos Aires y los gobiernos de Mendoza, San Juan y Corrientes, todos pertenecientes al $\mathrm{PDN}^{42}$.

Cabe incorporar en este punto del discurso de Mario Bravo el papel que le confiere a la Iglesia Católica. Dentro de la concepción del proyecto como un instrumento político, el senador señaló a la institución como una de las más preocupadas en establecerlo como ley, tal como observamos en el conjunto de organizaciones católicas mencionadas. Por otra parte, Bravo puntualizó el acercamiento de esta institución religiosa a la presidencia de Justo, ejemplificando con la activa participación del presidente en el Congreso Eucarístico Internacional de 1934 y la incorporación de educación religiosa en las escuelas primarias públicas realizada por algunas provincias, como el

\footnotetext{
${ }^{39}$ Cámara de Senadores..., Sesión 11 de diciembre de 1936, P. 1708. Esta tesis de la "solución fácil” ya es señalada en un trabajo específico sobre el debate realizado por José Luis Carnaghi, "La Ley de represión a las actividades comunistas de 1936: miradas y discursos sobre un mismo actor”, en Revista Escuela de Historia, año 6, vol. 1 nro. 6, 2007, p. 15.

40 Apéndice. Inserciones solicitadas por el Señor Senador Mario Bravo, sesión 15 de diciembre de 1936, pp. 1733-1767.

${ }^{41}$ Las huelgas de los trabajadores algodoneros correspondieron a un ciclo de protestas que se extendieron entre 1934

a 1936. Ver Cámara de Senadores..., Apéndice. Inserciones solicitadas por el Señor Senador Mario Bravo, sesión 16 de diciembre de 1936, pp. 1791-1800.

42 En los trabajos de Seveso y de Mariela Rubinzal el caso Fresco resulta central en estas políticas de disciplinamiento; Rubinzal agrega la influencia del pensamiento antiliberal de los nacionalistas en las políticas laborales de ese gobernador, subrayando que las mismas fueron acompañadas por medidas represivas contra la propaganda y accionar comunistas. Rubinzal, op. cit., pp. 104-110.
} 
caso de Catamarca ${ }^{43}$.

Vale introducir aquí el comentario realizado por Lisandro de la Torre, quien en su intervención denunciaba la relación entre conservadores e Iglesia. Sin embargo, el senador demócrata progresista no empleó ese vínculo simplemente para discutir la relación Estado-Iglesia sino para responderle a Sánchez Sorondo sobre el internacionalismo del PCA:

"Digo que la dependencia de la curia romana en que está esa Iglesia costeada por el Estado, acarrea consecuencias muchos más graves en las que puede acarrear las relaciones del pequeño Partido Comunista con la III Internacional., ${ }^{44}$

Otras de las instituciones referidas por Bravo fue la Policía y su accionar al que incluyó dentro de la "solución fácil" del Estado. El senador consideró a los hechos violentos en huelgas y protestas como consecuencia del proceder policial. Aquí incorporó el papel de la SERC, a la que calificó como una dependencia encargada de perseguir extremistas y de "confeccionar" prontuarios. Esta "confección", de acuerdo al senador, implicaba la elaboración de informes sin control a fin de justificar la represión ejercida por la Policía ${ }^{45}$. Según Bravo este tipo de procedimientos también eran llevados a cabo por la Justicia argentina: “...están creando una nueva categoría de rebeldes, de rebeldes sin doctrina...” a merced de denuncias abusivas, basadas en la falta de observación.

Es interesante destacar en lo expuesto sobre la Policía y las referencias al PC cómo Bravo refuerza la idea de un anticomunismo sin comunismo, reiterada por Lisandro de la Torre. El senador por Santa Fe inició su exposición discutiendo sobre la existencia real del peligro comunista, concluyendo que ese temor era infundado dado el relativo número de militantes del PC, lo cual implicaba desdeñar la utilidad del proyecto. De esta posición es que se desprende el análisis sobre el debate por la ley realizado por Rouquié. Este autor, al centrarse en las exposiciones de los senadores del PS y del PDP, concluye que el proyecto fue elaborado con el fin de atentar contra el "Frente Popular", interpretado como una estrategia contra el fraude conservador y el fascismo. Rouquié considera al FP como una alianza en defensa de valores democráticos, idea que tal vez sí lo era para Lisandro de la Torre, pero no así para las izquierdas o la posición del PC. Para de la Torre el control obrero se ocultaba detrás del "espantajo del comunismo" 46 , una invención de la policía para limitar las libertades existentes en un país gobernado por quienes califica como déspotas. No hay que menospreciar el hecho que distintos partidos del FP, en particular el PS, tendían a minimizar la presencia del PC en esa alianza. En base a ello es que Rouquié abona su hipótesis de una "máscara comunista", idea replicada por Zanatta, David Rock y José Luis Carnaghi (este último en un trabajo específico sobre el debate de la ley ${ }^{47}$ ).

\footnotetext{
43 Ello se relaciona con la tradición laicista del PS en su programa y en sus políticas a lo largo de su historia. Por otro lado, cabe destacar que la fuerte presencia de la Iglesia católica en el Estado de los años '30 fue fomentada en particular por el gobierno de A. P. Justo. Algunos autores califican esta situación como una recuperación del papel de la Iglesia a nivel público y social (Zanatta, op. cit.). Otros aseguran que ello formó parte de un proceso de acción social y política que tuvo inicio desde las primeras décadas del siglo (Lida, Miranda, "El catolicismo de masas en la década de 1930. Un debate historiográfico", en Folquer-Amenta (eds), Sociedad, cristianismo y política. Tejiendo historias locales, San Miguel de Tucumán, Editorial UNSTA, 2010.)

${ }^{44}$ Cámara de Senadores..., Sesión 21 de diciembre de 1936, pp. 1876-1877.

45 En relación a ello comenta haber conocido a un individuo llamado Schroeders quien dijo haber aportado información a la Sección para preparar los prontuarios de los perseguidos comunistas. Cámara de Senadores..., Sesión 17 de diciembre de 1936, pp. 1824-1827.

${ }^{46}$ Cámara de Senadores..., Sesión 21 de diciembre de 193Cámara de Senadores..., Sesión 21 de diciembre de 196,6, pp. 1862-1863.

47 En el análisis acerca del proyecto de Ley, este autor sugiere que funcionó como un "termómetro" de la discusión acerca del comunismo, reiterando como parte de su tesis la falta de contenido realista del proyecto dado el "escaso número de militantes del PCA", razón dada por de la Torre en el debate. En Carnaghi, José Luis, op.cit.
} 
Podemos agregar en este punto la existencia de cartas o documentos de rechazo a la ley elaborados por distintos sindicatos y remitidos al Senado de la Nación. La mayoría de éstos consideró a la ley como una "expresión fascista" y/o una herramienta de control sobre el movimiento obrero, sin para eso negar la existencia del comunismo ${ }^{48}$. Entre quienes adscribieron a esta posición encontramos tanto a la Federación Obrera Nacional de la Construcción, como al Sindicato Único de Obreros en Madera y Anexos, Sindicato Obrero de la Industria Metalúrgica, Pintores, de Biseladores y Anexos, del Gremio Gastronómico, la Unión Obrera Textil, La Fraternidad, Empleados de Farmacia, la Federación Gráfica Bonaerense y la Federación Obrera Provincial Mendocina.

A diferencia de Mario Bravo que rescataba la especificidad del proyecto, de la Torre insistió en que el "espantajo comunista" incluía un abanico de posibilidades desde quiénes detentaban un pensamiento democrático hasta aquellos que expresaban ideas consideradas equivocadas por la comisión evaluadora del proyecto, pasando especialmente por los que luchaban contra el fascismo. Este razonamiento a través del cual se criticaba la ley por antidemocrática y no por anticomunista resulta negador del comunismo al tiempo que minimizaba la capacidad combativa del sector obrero vinculado a las izquierdas:

“... yo no creo que la revolución social sea empresa tan fácil como pretenden los reaccionarios cuando se valen de argumentos para la represión" ${ }^{49}$.

En resumen, de la Torre no presentó relación entre este proyecto de represión y el escenario de conflicto social existente en el país. Así como Bravo vinculaba esas problemáticas con el debate, el senador santafesino recurrió a descalificar el accionar de quienes la elaboraron, asociando tanto a conservadores como nacionalistas al fascismo. Quienes eran reales para de la Torre eran los anticomunistas, considerando como tales a las compañías extranjeras ${ }^{50}$ y los partidos políticos vinculados a la reacción.

De las intervenciones adherentes al proyecto, una de las más destacadas fue la de José Heriberto Martínez, de la provincia de Córdoba. Por empezar, partiendo de acusar al régimen comunista de la URSS como antidemocrático, empleó el argumento sobre la difusión de ideas adversas al Estado y sociedad argentinos, disruptivas del orden constitucional y tendientes al establecimiento de un régimen dictatorial. Su punto era descalificar la idea del fantasma, para lo cual la violencia revolucionaria y los parámetros por fuera de un orden legal democrático emergieron como motivo para justificar el control al comunismo. Martínez consideró como primer ejemplo de ello al escenario de la Europa no soviética en la que los FP habían llegado al poder estatal o tenían fuerte presencia:

"La experiencia del gobierno de Blum, en ese sentido, no ha sido satisfactoria. En Francia se han ocupado fábricas, las libertades han sido suprimidas, las revueltas han cundido y ya han llegado las cosas a tales extremos que esos partidos de tendencia moderada, como el Partido Radical y el Radical Socialista (...) si bien no han establecido la ruptura definitiva del Frente Popular, han hecho declaraciones procurando encauzar su hábito legal al país..."

\footnotetext{
48 Archivo Memoria Legislativa de la Honorable Cámara de Diputados, “Telegramas de adhesión y oposición”, en Ley de Represión al comunismo, noviembre de 1936.

${ }^{49}$ Cámara de Senadores..., Sesión 21 de diciembre de 1936, pp. 1864-1866.

50 Cita el caso particular de la empresa petrolera soviética Iuyamtorg y las presiones de capitales ingleses y norteamericanos antes la presencia de esa compañía en Argentina. Cámara de Senadores..., Sesión 22 de diciembre de 1936, 1895-1897.

${ }^{51}$ Cámara de Senadores..., Sesión 23 de diciembre de 1936, pp. 1924-1925.
} 
Además de reiterar el argumento sobre el internacionalismo del PCA, Martínez enunció una serie de conflictos obreros ocurridos en el país en los que el Departamento Nacional del Trabajo intervino. Su conclusión fue que las mediaciones ofrecidas por ese Departamento sólo constituían más obstáculos, siendo más viables aquellas negociaciones en los que el mismo no tuvo participación. Para este senador la negociación laboral debía realizarse sin intermediarios estatales ni sindicales para lograr el cumplimiento del derecho a la libertad de trabajo, al tiempo que remarcaba como reivindicaciones justas aquellas de carácter estrictamente laboral y no gremiales.

En relación a esto último, tomó el caso de la actuación del PC en la provincia de Córdoba, tema mencionado a lo largo del debate. El interés de Martínez radicaba en resaltar las particularidades de las prácticas sindicales de los comunistas argentinos, quienes según su análisis aprovechaban el escenario de conflicto social imperante para avanzar con su dominio sobre la clase trabajadora. Por ende consideró que el avance de doctrinas como la comunista se vinculaba a los cambios económicos del período. De acuerdo al senador estas transformaciones debían ser contempladas por el Estado y los empresarios a fin de solucionar la conflictividad existente y evitar así la propagación de esas ideas antisociales:

“...ha quedado demostrado que la experiencia marxista ha fracasado (...) Es evidente también que el régimen capitalista ha de sufrir las modificaciones necesarias que lo adapten a las nuevas condiciones. (...) El progreso técnico no debe significar una disminución de la mano de obra, sino que al contrario las ventajas de ese progreso deben ser aprovechadas por los trabajadores mediante la reducción de la jornada de trabajo y aumento correlativo de salarios (...) Debemos, entonces, señor presidente, armar a la sociedad con los instrumentos necesarios para impedir la propagación de doctrinas cuya aplicación ya sabíamos las consecuencias catastróficas que tiene." 52

El argumento sobre el atentado a la libertad de trabajo es también expuesto por Martínez a través de otro apéndice documental compuesto por dos notas periodísticas correspondientes a La Prensa (“Agitación en la campaña de Córdoba”) y La Nación ("Contra la libertad de trabajo"). En ellos se describen las actividades sindicales o de propaganda realizadas por huelguistas y/o activistas pertenecientes a izquierdas radicalizadas o comunistas en el mes de diciembre de ese año. Otro documento incluido consta de una carta de vecinos de Río Segundo (Córdoba) denunciando un acto anarquista y antifascista en apoyo a la República española.

Esta idea del avance de la organización del movimiento obrero ante la falta de soluciones por el Estado y empresarios se reitera en la exposición de Héctor González Iramaín, representante por La Rioja y a favor de la posible ley. En base a esa premisa, criticó los argumentos de Bravo sobre del disciplinamiento de la clase obrera. Para ello aludió que la aplicación de una ley de represión al comunismo no sería un atentado contra las organizaciones sindicales sino en favor de ellas ${ }^{53}$. Haciendo referencia a las discusiones ocurridas en la $\mathrm{II}^{\circ}$ Internacional, en especial a los escritos de Eduard Bernstein, calificó al comunismo como antidemocrático, antisocialista y con prácticas violentas y antisociales. No sólo buscó descalificar a esa organización sino que apuntó a quienes pretendían participar del Frente Popular, como la Unión Cívica Radical.

Una serie de informes que acompañaron la exposición respaldaron la visión del senador de esta ley como protectora de las organizaciones sindicales. El apéndice comprendió, en primer lugar, un documento que enumeraba con nombre y apellido aquellos militantes acusados de comunistas,

\footnotetext{
52 Cámara de Senadores..., Sesión 23 de diciembre de 1936, pp. 1949-1951.

${ }^{53}$ Cámara de Senadores..., Sesión 24 de diciembre de 1936, pp. 2060-2062.
} 
y, en segundo lugar, material sobre las negociaciones laborales de sindicatos de la provincia de Buenos Aires con el Departamento Provincial de Trabajo de Buenos Aires (DPT). A diferencia de Martínez, este senador enfatizó la importancia de ese tipo de organismos, presentando los agradecimientos al DPT bonaerense por su intermediación de parte de cada una de las organizaciones gremiales del documento entre las cuales se cuenta a distintos sindicatos del rubro de la construcción, del comercio, de frigoríficos, del transporte y metalúrgicos, pertenecientes a varias localidades bonaerenses.

Ratificando su posición acerca del comunismo, González Iramain resaltó que el éxito de las medidas del DPT bonaerense fue posible por el marco de restricciones impuestas al PCA por el gobierno de Manuel Fresco. Su conclusión es que la combinación de la intervención estatal y un debido control de la actividad revolucionaria del comunismo permitiría la disminución o solución pacífica de los conflictos obreros:

“... después de dictado el decreto contra el comunismo, decreto que en nada estorba la acción del departamento, sino que la facilita de la misma manera que a los gremios obreros serios y responsables le facilita su acción el hecho de verse libres de elementos perturbadores que en cada huelga o conflicto minúsculo entre el capital y el trabajo quieren encontrar la oportunidad de promover el comienzo, o cosa así, de la revolución social." ${ }^{54}$

El rechazo definitivo al proyecto de Ley de Represión tuvo lugar en los últimos días del año '36, siendo la violación a las garantías constitucionales el fundamento con el que se puso fin al debate. La visibilidad de esa justificación soslayó la presencia de la cuestión obrera y su vinculación a la presencia de las izquierdas radicalizadas. La cuestión comunista encerró en los años treinta las problemáticas que representaron las acciones de lucha de un sector de la clase trabajadora que había adquirido nuevas estrategias defensivas y complejizado sus organizaciones. En ello, el PC jugó un papel central; su actuación política resultó una novedad en los años treinta, en especial para el aparato represivo que procedió en consecuencia a hacer más específicas sus metodologías. El comunismo, ya presente en la política internacional, ahora se convertía en un temor real y concreto, que tanto el Estado argentino como distintas corrientes políticas locales buscaban disciplinar junto a otras izquierdas radicalizadas.

La cuestión comunista fue la forma que adquirió la cuestión obrera en los años treinta. El debate por la ley de represión señaló la necesidad de atacar aquellas conflictividades del mundo del trabajo buscando silenciar a un actor clave en éste. Las modalidades represivas desplegadas hasta ese momento junto a políticas de proscripción, como las impulsadas a nivel provincial en distintos casos, replicaron ese objetivo sostenido por sectores del nacionalismo reaccionario. El ataque a la propaganda comunista, punto base del proyecto, buscaba controlar la difusión de esas nuevas estrategias que no habían podido ser neutralizadas; el objetivo era evitar que el movimiento obrero adoptara o fuese hegemonizado por corrientes revolucionarias. El comunismo argentino representó ese temor a desactivar aún cuando estaba llevando a cabo una estrategia política parlamentarista alejada de otras posiciones de confrontación que alguna vez sostuvo ${ }^{55}$. Llamativamente, el FP significó una amenaza aún mayor para los anticomunistas que las propias acciones violentas en el escenario de huelga.

Por otra parte, esta necesidad de controlar las posiciones obreras más radicalizadas encontró una

\footnotetext{
${ }^{54}$ Cámara de Senadores..., Sesión 24 de diciembre de 1936, p. 2062.

${ }^{55}$ Como el caso de la estrategia de clase contra clase impulsada por la IC y aplicada por el PC local entre 1928 a 1935.
} 
nueva variable: la intervención estatal en el conflicto obrero. La mediación del Estado fue complemento de un tipo de represión al tiempo que volvió innecesarias otras medidas como la proscripción política. Correspondería preguntarnos sobre el nivel incidencia de la cuestión comunista en la ampliación del aparato de intervención y negociación laboral, y cómo ello reforzó una dicotomía ya presente, aquella que separaba a los reclamos "legítimos" de algunos obreros de la "agitación profesional" producida por otros. Si bien esta última propuesta excede al análisis del debate legislativo, emerge como un interrogante necesario y próximo a analizar.

\section{Bibliografía}

Caimari, Lila (2012), Mientras la ciudad duerme. Pistoleros, policías y periodistas en Buenos Aires, 19201945, Buenos Aires: S.XXI.

Camarero, Hernán, A la conquista de la clase obrera. Los comunistas y el mundo del trabajo en la Argentina, 1920-1935, Buenos Aires, S.XXI, 2007.

Carnaghi, José Luis, "La Ley de represión a las actividades comunistas de 1936: miradas y discursos sobre un mismo actor", en Revista Escuela de Historia, año 6, vol. 1 nro. 6, 2007.

Carrera, Nicolás Iñigo, La estrategia de la clase obrera. 1936, Buenos Aires, Ed. PIMSA, 2000.

Del Campo, Hugo, Sindicalismo y peronismo. Los comienzos de un vínculo perdurable, Buenos Aires, Siglo XXI, 2005.

Devoto, F., Nacionalismo, fascismo y tradicionalismo en la Argentina moderna, S. XXI, Buenos Aires, 2002.

Dolkart, Ronald, "La derecha durante la década infame", en Dolkart-McGee Deustch (compiladores), La derecha argentina, Buenos Aires, Ediciones B, 2001.

Finchelstein, Federico, Fascismo, liturgia e imaginario. El mito del general Uriburu y la Argentina nacionalista, FCE, Buenos Aires, 2002.

Gaudio Ricardo y Jorge Pilone (1988), "Estado y relaciones laborales en el período previo al surgimiento del peronismo, 1935-1943", en Juan C. Torre (comp.), La formación del sindicalismo peronista, Buenos Aires, Legasa, pp. 55-98.

Korzeniewicz, Roberto, "Las vísperas del peronismo. Los conflictos laborales entre 1930 y 1943", en Desarrollo Económico, vol. 33, nro. 131, Buenos Aires, octubre-diciembre de 1993.

Lida, Miranda, "El catolicismo de masas en la década de 1930. Un debate historiográfico", en Folquer-Amenta (eds), Sociedad, cristianismo y política. Tejiendo historias locales, San Miguel de Tucumán, Editorial UNSTA, 2010.

Lobato, Mirta Zaida, La vida en las fábricas. Trabajo, protesta y política en una comunidad obrera, Berisso (1904-1970), Buenos Aires, Prometeo, 2002.

Lvovich, Daniel, Nacionalismo y Antisemitismo en la Argentina, Buenos Aires, Ediciones Vergara, 2003.

McGee Deutsch, Sandra, Contrarrevolución en Argentina, Buenos Aires, UNQui Editorial, 2003. Finchelstein, Federico, Fascismo trasatlántico. Ideologia, violencia y sacralidad en Argentina y en Italia, 1919-1945, Fondo de Cultura Económica, Buenos Aires, 2010.

McGee Deutsch, Sandra, Las derechas. La extrema derecha en la Argentina, Brasil y Chile 1890-1939, UNQui Editorial, Buenos Aires, 2005.

Rapalo, María Ester, Patrones y obreros. La ofensiva de la clase propietaria, 1918-1930, Buenos Aires, Siglo XXI, 2012.

Rock, David, La Argentina Autoritaria, Buenos Aires, Ariel, 1993.

Rouquié, Alan, Poder militar y sociedad politica en la Argentina, tomo I, Bs. As., Emecé, 1981 (primera 
publicación en 1978).

Rubinzal, Mariela, El Nacionalismo frente a la cuestión social en la Argentina. Discursos, representaciones y prácticas de las derechas sobre el mundo del trabajo, Tesis Doctoral, La Plata, Universidad Nacional de La Plata - Facultad de Humanidades y Ciencias de la Educación, 2012.

Seveso, César, "A new Law for a new crime:Anticommunism in Argentina 1930-1940", en Journal of Iberian and Latinoamerican Studies, 13:1, July, 2007.

Ubertalli, José Luis, El enemigo rojo. La represión al Comunismo en la Argentina, Bs. As., Acercándonos ediciones, 2010.

Zanatta, Loris, Del Estado Liberal a la Nación Católica. Iglesia y Estado en los orígenes del peronismo, 19301943, UnQui Ed., Bernal (Buenos Aires), 1996. 